\title{
Enteral tube feeding: Safety and tolerance of nutritional supplements in hospitalized patients
}

\author{
Atul Kakkar ${ }^{1}$, Chetan Mehndiratta ${ }^{2 *}$ and Tanmay Agrawal ${ }^{2}$ \\ ${ }^{1}$ Sir Gangaram Hospital, New Delhi \\ ${ }^{2}$ Signutra Inc., New Delhi
}

\begin{abstract}
Objective: Most of the patients in intensive care unit (ICU) present nutritional challenges which needs to be compensated using enteral tube feeding (ETF). Maxvida $^{\mathrm{TM}}$ is a commercially available balanced nutrition supplement with antioxidants, bone strengthening and hemoglobin forming nutrients. However, its benefits in patients have not yet been established. Therefore, the present study aimed to assess the efficacy and tolerability of Maxvida ${ }^{\mathrm{TM}}$ in ICU patients.
\end{abstract}

Design: This was a two-week, prospective, open label, investigator-initiated study conducted between June-2016 to August-2016.

Methods: Participants of either sex, aged $\geq 18$ years, hospitalized for minimum two days, requiring enteral feeding were given two feeds of Maxvida ${ }^{\text {TM }}$ (30 gm diluted in $100 \mathrm{~mL}$ of water) along with four standard kitchen feeds at different timings. Primary endpoint was to monitor continuous GI tolerance. Secondary endpoints were change in leukocyte count, nutrient, renal, hepatic and hematological parameters. Data was analyzed descriptively using paired t-test and $p$ value of $<0.05$ was considered statistically significant.

Results: Fifteen (11 males, 4 females, mean age: $46.3 \pm 8.9$ years) participants were enrolled. None of them reported gastric intolerance. A significant improvement in hemoglobin $(\mathrm{p}=0.03)$, hematocrit $(\mathrm{p}=0.003)$, white blood cells $\left(\mathrm{p}=0.0001^{*}\right)$ levels was reported while RBC, platelet, differential leukocyte count also improved gradually.

Conclusion: Maxvida ${ }^{\mathrm{TM}}$ administered with hospital kitchen feed were found to be safe and gastro-intestinally well tolerated by all the participants.

\section{Introduction}

Patients in intensive care unit (ICU) face many complexities due to their health status. Malnutrition is one among them and is commonly observed in $30-50 \%$ of the hospitalized patients [1]. Poor nutrition reserve is observed during presentation or it develops during hospitalization (also known as hospital malnutrition), resulting in poor clinical outcomes including morbidity and mortality [2]. The major reason behind malnutrition in ICU patients is decreased intake of food due to illness associated depression, anxiety, gastrointestinal problems, etc [2].

In the recent years, enteral tube feeding (ETF) has played a key role in providing nutrition to critically ill patients. It is mainly used in patients who cannot attain adequate amount of food intake orally due to difficulty in eating or drinking [3]. To resolve nutrition related challenges, patients are fed or nourished with enteral feeding (EF). EF involves nourishment of patients with homogenized food and liquid with the help of a special tube which is inserted in patient's digestive tract [4]. However, ETF is also associated with various formula related challenges such as gastrointestinal disorders; infection related challenges such as pneumonia, tube site infection; metabolic challenges such as refeeding syndrome, hyperglycemia and mechanical challenges leading to tube blockage; [5].

Variety of commercial, nutrient specific EF formulas are available in the market and being used widely to nourish ICU patients. Generally, the factors affecting the selection of formula include nutritionist's experience and availability as well as price of the feed formula [4].
Maxvida $^{\mathrm{Tn}}$ is a commercial balanced nutrition supplement nourished with 32 key nutrients. It helps in improving nutritional health and well-being of patients. It is cholesterol, trans-fat and gluten free, therefore is acceptable for patients with hyperlipidemia. In addition to its nutritional benefits, it contains antioxidants, bone strengthening nutrients and helps in normal hemoglobin formation [6]. However, its benefits in patients have not yet been established. Therefore, the present study aimed to assess the efficacy and tolerability of Maxvida ${ }^{\text {Tw }}$ in ICU patients.

\section{Methods}

This was a 2-week, prospective, open label, investigator-initiated study conducted between June-2016 to August-2016. Fifteen adult participants, of either sex, aged 18 years and above, hospitalized patients, requiring enteral feeding, with minimum 2 days of hospital stay were included in the study. Participants received tube feeding prior to hospitalization, history of renal, hepatic, cardiovascular, respiratory, skin, haematological, endocrine, neurological or gastrointestinal diseases, and with any evidence of organ dysfunction or any clinically

${ }^{\star}$ Correspondence to: Dr Chetan Mehndiratta, Signutra, MZ-7 Floor, Modi Tower 98, Nehru Place, New Delhi-110019, India, Tel: 9920590710; E-mail: chetan2882@gmail.com

Key words: tube feeding, enteral feed, ICU, Maxvida, nutritional supplement

Received: September 29, 2019; Accepted: October 09, 2019; Published: October 14,2019 
significant deviation from the normal, in physical or clinical determinations were excluded. Data of participants receiving 2 Feeds of Maxvida $^{\text {max }}$ (30 gm diluted in $100 \mathrm{~mL}$ of water) was administered per day at $08.00 \mathrm{hrs}$ and $16.00 \mathrm{hrs}$. The hospital feed included $350 \mathrm{ml}$ each of a standard kitchen feed administered at $10.00 \mathrm{hrs}, 12.00 \mathrm{hrs}, 18.00$ hrs and $20.00 \mathrm{hrs}(1 \mathrm{ml}$ of the hospital kitchen feed translated into 1 $\mathrm{kcal})$. The Gastric residual volume (GRV) was checked at $07.30 \mathrm{hrs,}$ $09.00 \mathrm{hrs}, 15.30 \mathrm{hrs}, 17.00 \mathrm{hrs}$.

The study was performed in compliance with the principles of the Declaration of Helsinki, in accordance with the International conference of harmonization guideline for good clinical practice, and in accordance with applicable regulatory requirements. All participants provided a written informed consent.

\section{Endpoints}

The primary endpoint was to monitor continuous GI tolerance and the following parameters were included: the number of diarrhea free days, stomach irritation, regurgitation, abdominal bloating, vomiting and GRV > $500 \mathrm{ml}$.

Secondary endpoints measured were change in haematological parameters (complete hemogram, creatinine, liver function tests (LFT's)- ALP, ALT, AST, Total bilirubin, Distribution of Serum Albumin level, Mean change in Serum Albumin level from Day 1 to subsequent days, Blood Urea Nitrogen (BUN) and comparison of pre to post mean values of nutrient parameters (Magnesium and Sodium). Adverse event monitoring included vital signs and potential abnormalities in the laboratory parameters.

\section{Statistical analysis}

Descriptive statistics for continuous variable and frequency with percentage for categorical variables were performed. Data were analysed and the mean data along with the standard deviation (SD) were subjected to statistical analysis using paired t-test. A ' $p$ ' value of less than 0.05 has been marked significantly difference from the pre values.

\section{Results}

Total 15 participants having normal physical examination were enrolled in the study; of these all participants completed the study (Figure 1).

As a standard of care, hospital maintains a minimum calorie requirement of $1600 \mathrm{kcal} /$ day for hospitalized patients.

Hospital Kitchen Feed: The calorie content of Hospital Kitchen Feed was $1 \mathrm{kcal} / \mathrm{ml}$. Four servings of $350 \mathrm{ml}$ each of hospital feed translated to $1400 \mathrm{kcal}$ of energy provided to participants per day.

\section{Maxvida $^{\text {tw }}$ nutritional profile}

Nutritional profile obtained below shows daily energy requirements were met by $60 \mathrm{~g}\left(30 \mathrm{~g}^{\star} 2\right)$ of Maxvida ${ }^{\mathrm{Tw}}$ (244 kcal/day) (Table 1$)$.

\section{Demographics}

Mean age and BMI of the study participants were $46.3 \pm 8.9$ years and $27.6 \pm 16.0 \mathrm{~kg} / \mathrm{m}^{2}$, respectively. Study population included more males $(\mathrm{n}=11 ; 73.3 \%)$ than females $(\mathrm{n}=4 ; 26.7 \%)$ as shown in table 2 . $60 \%$ of participants were $<50$ years of age.

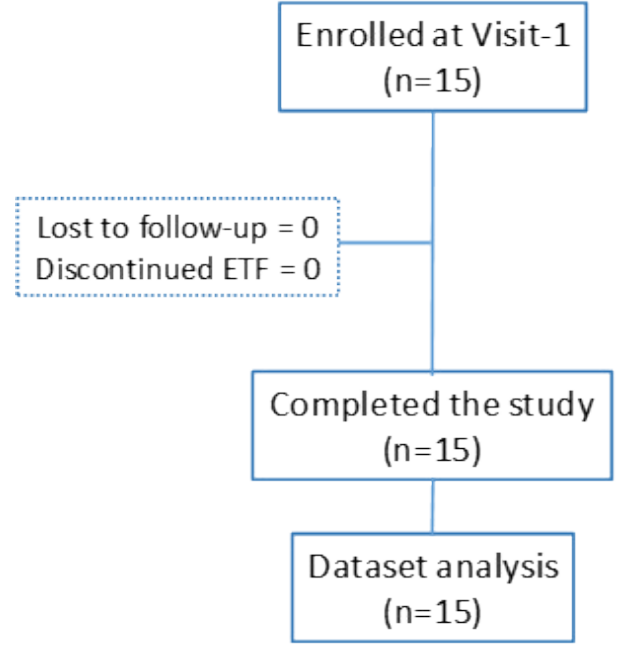

Figure 1. Participant disposition

Table 1. Nutritional profile for Maxvida ${ }^{\mathrm{TM}}$

\begin{tabular}{|c|c|c|c|}
\hline S. No. & Nutrients & Unit & Per 100 g \\
\hline $\mathbf{1}$ & Energy (Total) & kcal & 408 \\
\hline $\mathbf{2}$ & Total Fat & $\mathrm{g}$ & 12 \\
\hline $\mathbf{3}$ & Saturated Fat & $\mathrm{g}$ & 3.5 \\
\hline $\mathbf{4}$ & MUFA & $\mathrm{g}$ & 5 \\
\hline $\mathbf{5}$ & PUFA & $\mathrm{g}$ & 3.5 \\
\hline $\mathbf{6}$ & Proteins & $\mathrm{g}$ & 15 \\
\hline $\mathbf{7}$ & Carbohydrates & $\mathrm{g}$ & 60 \\
\hline $\mathbf{8}$ & Sugar (Sucrose) & $\mathrm{g}$ & 13 \\
\hline $\mathbf{9}$ & Dietary Fiber & $\mathrm{g}$ & 3.2 \\
\hline
\end{tabular}

Table 2. Demographic distribution of study participants

\begin{tabular}{|c|c|c|}
\hline Age and Gender & No (n=15) & $\begin{array}{c}\text { Percentage of Participants } \\
\text { (\%) }\end{array}$ \\
\hline & Age in years \\
\hline$\geq 50$ & 9 & 60.0 \\
\hline Mean age \pm SD (Range) & 6 & 40.0 \\
\hline & $46.3 \pm 8.9(32.0-58.0)$ & \\
\hline Male & Gender \\
\hline Female & 11 & 73.3 \\
\hline & 4 & 26.7 \\
\hline
\end{tabular}

\section{Primary endpoints}

There were no events observed of any gastric abnormalities (diarrhea, stomach irritation, regurgitation, abdominal bloating and vomiting) for any of the participants. Gastric residual volume GRVs were within the limits $(<500 \mathrm{ml})$ for continual tube feeding in all participants showing positive signs of GI tolerance for feed (Figure 2). Distribution of GRV was $348.6,376.3,326.1 \& 318.0 \mathrm{ml}$ on day $1,2,3$ $\& 4$, respectively.

\section{Secondary endpoints}

Following are the results for comparison of pre and post mean values of haematological and blood nutrient parameters; distribution of serum albumin level, mean change in serum albumin level from day 1 to subsequent days and the adverse events observed during the clinical study period (Table 3 ).

The haematological and nutrient parameters were reported to improve gradually while stay of participants in hospital when fed 
Table 3. Comparison of hemoglobin $(\mathrm{Hb})$ from pre to post intervention

\begin{tabular}{|c|c|c|c|c|c|}
\hline Hematological parameters & Reference Range & $\begin{array}{c}\text { Pre } \\
(n=15) \\
(\text { Mean } \pm \text { SD })\end{array}$ & $\begin{array}{c}\text { Post } \\
(n=15) \\
(\text { Mean } \pm \text { SD })\end{array}$ & Mean change** & p-value \\
\hline $\mathrm{Hb}(\mathrm{g} / \mathrm{dL})$ & $\begin{array}{c}13.0-17.0 \text { (male) } \\
12.0-15.0 \text { (female) }\end{array}$ & $11.2 \pm 1.4$ & $11.6 \pm 1.3$ & $0.3 \pm 0.5$ & $0.03 * 1$ \\
\hline Platelet count (per cmm) & $150000-450000$ & $156666.7 \pm 58336$ & $358533.3 \pm 729081.0$ & $201866.7 \pm 688234.2$ & $0.20^{1}$ \\
\hline Hematocrit (\%) & $40-50$ & $35.3 \pm 27.6$ & $38.5 \pm 23.2$ & $3.14 \pm 3.3$ & $0.003 * 1$ \\
\hline \multicolumn{6}{|l|}{ DLC } \\
\hline $\begin{array}{l}\text { Segmented } \\
\text { Neutrophils (\%) }\end{array}$ & $40-80$ & $71.8 \pm 10.2$ & $67.9 \pm 7.2$ & $-3.93 \pm 6.7$ & $0.04 *$ \\
\hline Lymphocytes (\%) & $20-40$ & $21.1 \pm 8.3$ & $23.7 \pm 5.8$ & $2.7 \pm 5.9$ & $0.10^{1}$ \\
\hline Basophils (\%) & $0.1-2.0$ & $0.0 \pm 0.0$ & $0.1 \pm 0.3$ & $0.2 \pm 0.3$ & $0.33^{1}$ \\
\hline Monocytes (\%) & $2-10$ & $4.3 \pm 2.1$ & $4.4 \pm 2.4$ & $0.1 \pm 3.1$ & $0.93^{1}$ \\
\hline Eosinophils (\%) & $1-6$ & $2.7 \pm 2.6$ & $3.5 \pm 1.7$ & $0.8 \pm 3.0$ & $0.31^{1}$ \\
\hline RBC (million/ cmm) & $4.5-5.5$ & $4.0 \pm 0.9$ & $4.2 \pm 0.5$ & $0.2 \pm 1.0$ & $0.4^{1}$ \\
\hline WBC (per cmm) & $4000-10000$ & $16726.7 \pm 2365.4$ & $11666.7 \pm 3770.5$ & $-5060.0 \pm 3722.9$ & $0.0001 * 1$ \\
\hline Creatinine (mg/dL) & & $0.9 \pm 0.2$ & $0.9 \pm 0.2$ & $-0.2 \pm 0.4$ & $0.84^{1}$ \\
\hline \multicolumn{6}{|l|}{ LFT } \\
\hline ALP(IU/L) & & $147.9 \pm 101.9$ & $116.0 \pm 28.9$ & $-55.1 \pm 123.9$ & $0.43^{1}$ \\
\hline ALT(IU/L) & & $67.9 \pm 91.9$ & $36.2 \pm 23.4$ & $-39.0 \pm 83.4$ & $0.20^{2}$ \\
\hline AST(IU/L) & & $61.3 \pm 83.9$ & $35.2 \pm 16.9$ & $-33.2 \pm 76.1$ & $0.63^{2}$ \\
\hline Total Bilirubin (mg/dL) & & $0.9 \pm 0.8$ & $0.6 \pm 0.2$ & $-0.4 \pm 0.9$ & $0.7^{2}$ \\
\hline Blood Urea Nitrogen $(\mathrm{mg} / \mathrm{dL})$ & & $18.1 \pm 9.9$ & $23.1 \pm 12.2$ & $-1.2 \pm 18.1$ & $0.5^{1}$ \\
\hline Magnesium-Mg (mg/dL) & & $2.0 \pm 0.4$ & $2.1 \pm 0.3$ & $-0.3 \pm 0.8$ & 0.82 \\
\hline Sodium-Na (mg/dL) & & $134.9 \pm 9.3$ & $141.9 \pm 6.2$ & $-21.3 \pm 60.5$ & $0.02 *$ \\
\hline
\end{tabular}

${ }^{1}$ Paired t-test, ${ }^{2}$ Wilcoxon rank sum test *Significant, ${ }^{* *}$ Mean change is the mean of difference of individual pre and post values*

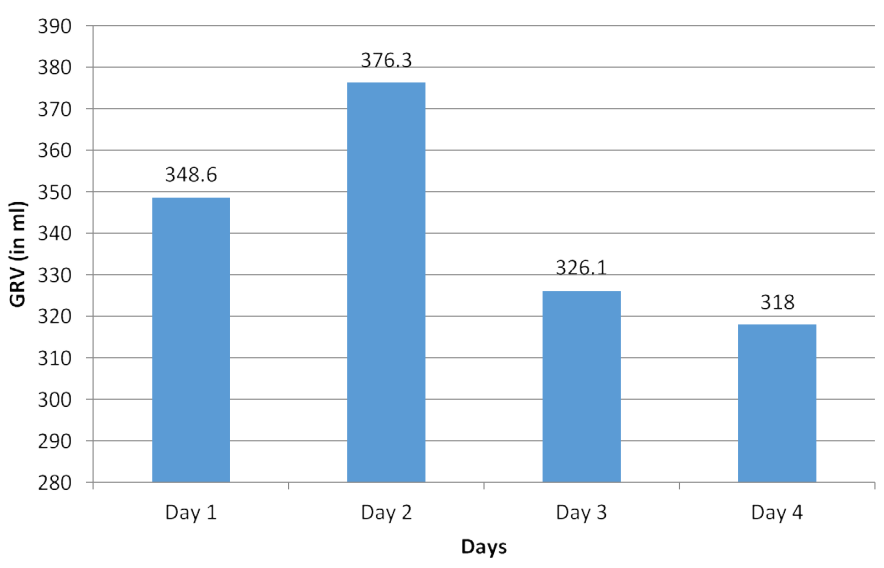

Figure 2. Distribution of GRV

with Maxvida $^{\mathrm{Tw}}$ supplement administered with hospital kitchen feed. Haemoglobin, platelet count, haematocrit values, RBC count, BUN and serum albumin levels were found to increase gradually whereas, the pre to post intervention values for WBC count and LFT parameters decreased, during the hospital stay of participants, signifying the reduced infection and improved immunological status of the participant's health.

\section{Safety}

No severe adverse event (AE) was reported. Of the AEs observed, one participant experienced headache during the study, which was reported as unrelated to the study product. Other AEs reported during this study were flatulence $(7 ; 0.5 \%)$, abdominal discomfort $(4 ; 0.3 \%)$, gastritis $(2 ; 0.1 \%)$, diarrhoea $(2 ; 0.1 \%)$ and leg pain $(1 ; 0.1 \%)$. Most of the AEs were mild $(n=14)$ and 2 were moderate.

\section{Discussion}

Commercial feed administered via ETF causes gastrointestinal discomfort. More than $60 \%$ ICU patients experience ETF related diarrhoea, which may lead to nutrient and fluid loss, as well as electrolyte imbalance. There are various causes of gastrointestinal intolerance including high food delivery rate, low fibre rich feed, infections, etc. [7,8]. Literature reported patients experience gastrointestinal complications as the most frequently faced challenge related to ETF [8]. In order to determine the gastrointestinal complications associated with the use of Maxvida ${ }^{\mathrm{mx}}$, the present study assessed gastrointestinal tolerance and reported no adverse events related to gastric abnormalities including diarrhoea, stomach irritation, regurgitation, abdominal bloating or vomiting.

Formulation related intolerance could be due to the presence of a specific ingredient or long-term use of the product [9]. In addition to the formula constituency, administration route, feeding modal, frequency, administration time and volume of doses, also play an essential role in reducing the risk of these complications [8]. Current observations suggest that Maxvida ${ }^{\text {ix }}$ ingredients and its formulation does not contain any components leading to gastrointestinal discomfort.

In the present study, various haematological parameters were also assessed. A significant improvement $(\mathrm{p}=0.03)$ in haemoglobin levels was observed, which confirmed the presence of haemoglobin boosting ingredients in the feed. Haematocrit levels were also increased significantly $(\mathrm{p}=0.003)$, while $\mathrm{RBC}$ showed a gradual improvement (mean change: $0.2 \pm 1.0 \mathrm{million} / \mathrm{cm}^{2}$ ). Thrombocytopenia is associated with compromised immunity and leads to decrease in platelet count $[10,11]$. Due to the presence of dietary ingredients of Maxvida ${ }^{\mathrm{mm}}$ that boosts the immune system, the platelet count increased from 156666.7 \pm 58336 to $358533.3 \pm 729081.0$. Leukocytes, which are involved in phagocytosis and play a significant role in body's defensive mechanism 
[12], was found to be significantly increased $\left(p=0.0001^{\star}\right)$ as seen in terms of WBC counts. DLC count was also improved after consumption of Maxvida ${ }^{\mathrm{Tx}}$ (\% mean change in segmented neutrophils= $-3.93 \pm 6.7$; lymphocytes $=2.7 \pm 5.9$; basophils $=0.2 \pm 0.3$; monocytes $=0.1 \pm 3.1$; eosinophils=0.8 \pm 3.0 ).

Malnutrition and gastrointestinal complications are also associated with liver functioning [12]. ICU patients have also been found with abnormal liver biochemical function tests due to acute hepatitis, acute liver failure, and drug-induced liver injury [13]. Therefore, it is essential to assess liver functioning enzymes in ICU patients to determine the effect of formula on the liver health. In the present study, there was no significant change in the LFTs parameters seen, but a trend was observed where values returned towards normal range.

ICU patients also face a high risk of acute kidney injury, which also raises the risk of mortality. More than $30 \%$ of ICU patients suffer from kidney dysfunction of some degree [14]. In the present study, the creatinine level was stable and BUN levels increased gradually, supporting that the formula is safe and well tolerated by the kidneys. In addition, the magnesium and sodium levels also improved in the present study signifying the improved cellular functions.

Overall, Maxvida $^{\mathrm{Tw}}$ is not associated with any adverse event and is well tolerated by all participants. It also improved the haematological, nutritional, hepatic, kidney and immunity related parameters, thereby boosting the overall immunity of the body. This suggests the use of the feed in malnourished patients as well with weak immune system.

\section{Conclusions}

Primary and Secondary outcomes of the study where Maxvida ${ }^{\text {Tx }}$ was administered with hospital kitchen feed via ETF, was found to be safe and gastro-intestinally well tolerated by all the participating patients.

Ethics Compliance: All ethical approvals required for the study was obtained before the start of the trial.

\section{Conflict of interest}

None

\section{Funding}

The work was supported by Signutra Inc.

\section{Acknowledgements}

All named authors meet the International Committee of Medical Journal Editors (ICMJE) criteria for authorship for this manuscript, take responsibility for the integrity of the work and have given final approval for the version to be published. The authors wish to thank participating investigators for contributing participants' data for this study. The authors also acknowledge Dr. Punit Srivastava from MediCeption Science Pvt Ltd. for providing writing assistance, which were funded by Signutra Inc.

\section{References}

1. Powers J, Samaan K (2014) Malnutrition in the ICU patient population. Crit Care Nurs Clin North Am 26: 227-42. [Crossref]

2. Fuhrmann K, Panamonta N, Roaten S (2013) Malnutrition in the ICU: Current recommendations for the assessment of nutritional status and a review of the use of albumin as an indicator of malnutrition. The Southwest Respiratory Critical Care Chronicles 1: 8-14.

3. National Collaborating Centre for Acute Care (UK) (2006). Nutrition Support for Adults: Oral Nutrition Support, Enteral Tube Feeding and Parenteral Nutrition. London: (NICE Clinical Guidelines, No. 32.) 9, Enteral tube feeding in hospital and the community. [Crossref]

4. Hassan-Ghomi M, Nikooyeh B, Motamed S, R Neyestani T (2017) Efficacy of commercial formulas in comparison with home-made formulas for enteral feeding: A critical review. Med J Islam Repub Iran 31: 55. [Crossref]

5. Blumenstein I, Shastri YM, Stein J (2014) Gastroenteric tube feeding: techniques, problems and solutions. World J Gastroenterol 20: 8505-8524. [Crossref]

6. Maxvida ${ }^{\mathrm{TM}}$, Balanced Nutrition Supplement. Available from: http://www.signutra.com/ products.php?pid=1

7. Stroud M, Duncan H, Nightingale J (2003) Guidelines for enteral feeding in adult hospital patients. Gut 52:vii1-vii12. [Crossref]

8. Wanden-Berghe C, Patino-Alonso MC, Galindo-Villardon P, Sanz-Valero J (2019) Complications Associated with Enteral Nutrition: CAFANE Study. Nutrients 11: 9. [Crossref]

9. Commercial Formulas for the Feeding Tube. Available from: https:// oralcancerfoundation.org/nutrition/commercial-formulas-feeding-tube/

10. Qu M, Liu Q, Zhao HG, Peng J, Ni H, et al. (2018) Low platelet count as risk factor for infections in patients with primary immune thrombocytopenia: a retrospective evaluation. Ann Hematol 97: 1701-1706. [Crossref]

11. Blumenreich MS (1990) The White Blood Cell and Differential Count. In: Walker HK Hall WD, Hurst JW, editors. Clinical Methods: The History, Physical, and Laboratory Examinations. 3rd edition. Boston: Butterworths. Chapter 153. [Crossref]

12. Kalaitzakis E (2014) Gastrointestinal dysfunction in liver cirrhosis. World $J$ Gastroenterol 20: 14686-14695. [Crossref]

13. Koch A, Streetz K, Tischendorf J, Trautwein C, Tacke F (2013) Abnormal liver function tests in the intensive care unit. Med Klin Intensivmed Notfmed 108: 599-608. [Crossref]

14. Seller-Perez G, Herrera-Gutierrez ME, Maynar-Moliner J, Sanchez-Izquierdo-Riera JA, Marinho A, et al. (2013) Estimating kidney function in the critically ill patients. Crit Care Res Pract 721810. [Crossref]

Copyright: (C2019 Kakkar A. This is an open-access article distributed under the terms of the Creative Commons Attribution License, which permits unrestricted use, distribution, and reproduction in any medium, provided the original author and source are credited. 